\title{
La información y el conocimiento
}

\author{
Guido Américo Torres Castillo ${ }^{1,}$. \\ ${ }^{1}$ Escuela de posgrado de la Universidad Andina del Cusco, Cusco, Perú. \\ ”' gtorres@uandina.edu.pe
}

Siendo que la sociedad del conocimiento es una tendencia que sigue impactando en la comunidad científica mundial, confrontamos también la característica y exigencia de una sociedad de la información, asumiendo que información no es lo mismo que conocimiento pues la información es una herramienta del conocimiento. El término sociedad del conocimiento, le corresponde a Peter Drucker (1909-2005). En su libro Sociedad Poscapitalista publicado en 1993, Drucker afirma que lo que cuenta es la productividad de los trabajadores no manuales, es decir, aplicar el conocimiento al conocimiento y que la función de una organización es hacer productivos los conocimientos. La sociedad poscapitalista es una sociedad del conocimiento, no se fundamenta en el recurso de la producción, en la actual sociedad, es el saber el recurso clave más que el capital.

La Universidad Andina del Cusco ha mostrado su gran interés por desarrollar la investigación buscando convertirla en una buena costumbre de toda la comunidad universitaria. Se trata de aprovechar al máximo la generación de conocimiento y la producción intelectual y reflejarlo en la publicación de artículos originales, consecuencia de la investigación básica o aplicada, artículos que aparecen en este nuevo volumen. Es posible que estemos sembrando un futuro muy cercano que permitirá identificar a la Universidad como una gran fuente de conocimiento y ojalá alguna vez, como lo predijo Drucker, una industria del conocimiento. La revista Científico Cultural Yachay, refleja el interés de los investigadores por transmitir conocimiento a través de los artículos que publicamos.

El conocimiento o el saber que se genera con la investigación se convierte en un recurso importante para responder a las exigencias de la sociedad, el saber reside en nosotros los docentes, nuestros estudiantes y colaboradores administrativos, siendo así todos nos convertimos en trabajadores del conocimiento que, aun cuando sea un sueño, es un reto que autoridades, docentes, estudiantes y trabajadores, buscamos alcanzar.

El emprendimiento es otra característica que se va generando significativamente en nuestra institución universitaria que junto con la innovación busca la generación de conocimientos en base a la cognición. La mente a través del pensamiento, brinda el camino de la producción más que la mano de obra. Entonces es necesario que todos utilicemos la información que conlleva conocimiento.

La Revista se ratifica como un espacio que, respetuosa del punto de vista de sus autores, se constituye en un medio en el que la Universidad expresa sus propios valores, tendencias y sus intereses conectados a la solución de problemas de Cusco y el Perú.

Citar como: Torres, G. (2019). La información y el conocimiento. Rev Yachay, 8(1), 521

Rev Yachay volumen (8) Numero (1), enero-diciembre 2019 